\title{
Fea Based Validation of Weld Joints to Determine Effect of Overlap Length of Weld Strength
}

\author{
Mr. Ranjeet Patil ${ }^{1,}$, Mr. Amol Walvekar ${ }^{2}$ Mr. Kuldeep Kashid ${ }^{3}$ \\ ${ }^{1,2}$ Mechanical Engineering Dept. Padmabhushan Vasantraodada Patil Institute of Technology, Budhgaon, \\ Sangli Maharashtra, India, ${ }^{3}$ Shivaji University, Kolhapur; Maharashtra India;
}

\begin{abstract}
Welding is extensively used in fabrication as an alternative method for casting or forging and as a replacement for a bolted and riveted joint. Since it is related to human being, it is necessary to analysis the joint with prior attention to safely of its user. This paper investigate the deformation and equivalent Von Mises stresses of thin plate based on plate welding with varying overlapping length of plate. Firstly three dimensional Elastic Non-linear Finite Element model is used to compute welding deformation and stresses within a practical time.
\end{abstract}

\section{INTRODUCTION}

Due to the globalization, it is very much essential for the manufacturer to produce a goods having highest possible reliability. Basically a welded joint is a permanent joint which is obtained by fusion of the edges of the two plates to be joined together with or without application of pressure and filler material. Welding is extensively used in fabrication as an alternative method for casting or forging and as a replacement for a bolted and riveted joint. Since it is related to human being, it is necessary to design and analysis the joint with prior attention to safely of its user.

The inter-diffusion between the materials that are joined is the underlying principle in all welding processes. The diffusion may take place in the liquid, solid or mixed state. In welding the metallic materials are joined by the formation of metallic bonds and a perfect connection is formed. In practice however, it is very difficult to achieve a perfect joint; for, real surfaces are never smooth. When welding, contact is established only at a few points in the surface, joins irregular surfaces where atomic bonding occurs. Therefore the strength attained will be only a fraction of the full strength. Also, the irregular surface may not be very clean, being contaminated with adsorbed moisture, oxide film, grease layer etc. In the welding of such surfaces, the contaminants have to be removed for the bonding of the surface atoms to take place. This can be accomplished by applying either heat or pressure. In practical welding, both heat and pressure are applied to get a good joint.

A better approach to the prediction of welding deformation is using the combined technologies of experiments with numerical calculation. With modern computing facilities, the Finite Element (FE) technique has become an effective method for prediction and assessment of welding residual stress and distortionsvarious factors, the quantitative prediction and the control of welding deformation especially for a large and complex welded structure is extremely difficult.

\section{BRIEF OVERVIEW OF SOME RESEARCH}

As there are lot of work is done in weld of flat plate, very little work is done in relevant field of a welded joint of a curved plate. A brief review of some selected references on the strength of curved plate, distortions of plate, strength of welded joint.

A Joseph et. al. have suggested that dissimilar metal joints between different materials are widely used in steam generator of power plant. Failure analysis carried out on a dissimilar weld joint, a residual stresses in the weld joints are one of the main factor which causes failure in dissimilar weld joint. Residual stress profiles across these weld joints were determined by $\mathrm{X}$-ray diffraction technique. The failures are generally attributed to one or more of the following causes 1.Difference in mechanical properties across the weld joint and coefficient of

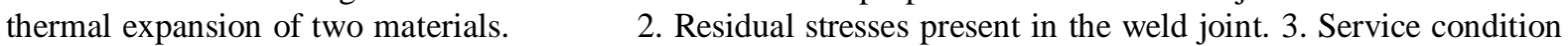
and others. A successful weld between dissimilar metal is one that is as strong as the weaker of the two metal being joined with sufficient tensile strength so that joint will not fail.

Chien-Yuan Hou has suggested that Fatigue analysis of welded joints usually assumes weld toes of 'mathematically perfect' geometry for the required weld toe stress state. However, the weld toe geometry certainly cannot be defined by simple mathematical functions. In that, the three-dimensional laser scanning technology used to preserve the real geometry of welded specimens. Finite element models of the specimens were then constructed with the scanned results. Linear elastic finite element analyses were then carried out to 
Deng et al. have predicted that welding distortions of large welded structure by using elastic Finite Element Analysis (FEA).Regardless of the types of the structures, the correction or straightening of the deformation, which required special skill and large cost, is an essential part in the assembly process. From the theoretical view point, thermal elastic plastic Finite Element Analysis the most general method to predict the welding residual stress and distortions. Based on the thermal elastic plastic analysis and experimental observations pointed out that a source resulting in welding deformation and residual stress must exist in the weld joint.

Hyungyil Lee el.al. have presented that the mechanical behaviour of a spot-welded specimen is generally approached in angles of overload and fatigue failures. Fatigue failure of spot-welded specimens can be dealt with a fracture parameter, since a spot-weld forms a singular geometry of external crack type. He expresses the limit loads in terms of base metal yield strength and specimen geometries. While spot-welding is generally used in the form of multi-spots, the fatigue strength of a multi spot- welded structure is eventually determined by the fatigue strength of each single spot-weld. Spot weld boundary is subjected to combined tension, bending and shear, therefore problem becomes an intrinsically there dimensional one. Wang and Ewing described the effect of material, shape, and radius of the nugget, width and thickness of the specimen.

M. Xiea,* J.C. Chapman have suggested that Friction-welded bar-plate connections are a basic structural component of Bi-Steel steel-concrete-steel sandwich construction. In Bi-Steel members, the bar-plate connections, embedded in concrete, are subject to tension, shear and bending. They describes experimental and numerical studies on the static and fatigue strength of the friction-welded connections with the bar loaded in tension. Finite element analysis is carried out to examine the effects of plate thickness, the collar ("flash") formed after friction welding, and possible initial defects or fatigue induced cracks. It is found that except for 6 $\mathrm{mm}$ plate specimens, the static tensile capacity of the embedded connections is governed by the tensile strength of the bar connectors. In the fatigue tests, single fracture and double fracture mechanisms were observed.

III. ANALYTICAL METHOD TO DETERMINE NON LINEAR STRENGTH

we will illustrate the finite element method using two sample problems from which the general method can be extrapolated. it is assumed that the reader is familiar with calculus and linear algebra.

p1 is a one-dimensional problem

P1: $\left\{\begin{array}{l}u^{\prime \prime}(x)=f(x) \text { in }(0,1), \\ u(0)=u(1)=0,\end{array}\right.$

where $f_{\text {is given, }} u$ is an unknown function of $x$, and $u^{\prime \prime}$ is the second derivative of $u$ with respect to $x$. the two-dimensional sample problem is the dirichlet problem

$$
\text { P2 : } \begin{cases}u_{x x}(x, y)+u_{y y}(x, y)=f(x, y) & \text { in } \Omega, \\ u=0 & \text { on } \partial \Omega,\end{cases}
$$

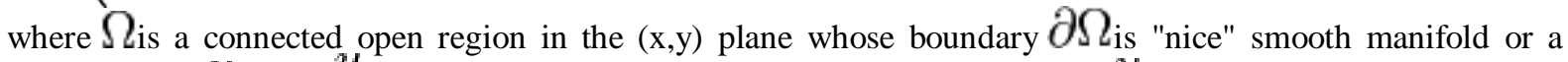

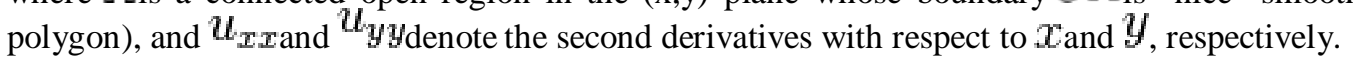

the problem p1 can be solved "directly" by computing ant derivatives. however, this method of solving the boundary value problem works only when there is only one spatial dimension and does not generalize to higherdimensional problems or to problems like $u+u^{\prime \prime}=f$. for this reason, we will develop the finite element method for $\mathrm{p} 1$ and outline its generalization to $\mathrm{p} 2$.

engineering structures, the joints are elements of a simple in structure having boundary conditions that may vary from those used in this analysis. Because the boundary conditions affect the results, joints were usually modeled as restrained so that the cracks propagated under force control. This is considered to provide conservative solutions.

\section{DIFFERENT TYPES OF NONLINEAR BEHAVIOR}

Although the process of changing stiffness is common to all types of nonlinear analyses, the origin of nonlinear behavior can be different, making it logical to classify nonlinear analyses based on the principal origin of nonlinearity. Because it isn't possible to point out a single cause of nonlinear behavior in many problems, some analyses may have to account for more than one type of nonlinearity.

\subsection{Nonlinear geometry}

As already discussed, nonlinear analysis becomes necessary when the stiffness of the part changes under its operating conditions. If changes in stiffness come only from changes in shape, nonlinear behavior is 
defined as geometric nonlinearity. Such shape-caused changes in stiffness can happen when a part has large deformations that are visible to the naked eye. A generally accepted rule of thumb suggests conducting a nonlinear geometry analysis if the deformations are larger than $1 / 20$ th of the part's largest dimension. Another important factor to recognize is that in cases of large deformations, the load direction can change as the model deforms. Most FEA programs offer two choices to account for this direction change: following and non following load

\subsection{Nonlinear material}

If changes of stiffness occur due only to changes in material properties under operating conditions, the problem is one of material nonlinearity. A linear material model assumes stress to be proportional to strain (Figure 6, below). That means it assumes that the higher the load applied, the higher the stresses and deformation will be, proportional to the changes in the load. It also assumes that no permanent deformations will result, and that once the load has been removed the model will always return to its original shape.

Changes in stiffness due to shape can also occur when the deformations are small. A typical example is an initially flat membrane deflecting under pressure. Initially, the membrane resists the pressure load only with bending stiffness. After the pressure load has caused some curvature, the deformed membrane exhibits stiffness additional to the original bending stiffness.

\subsection{Understanding Loss of elastic stability (buckling)}

Stiffness in a part also changes due to applied loads. Sometimes, loads-depending on how they are applied — can either increase the stiffness (tension loads) or decrease it (compressive loads). For example, a tight rope can take an acrobat's weight. A loose one, however, will make him fall. In cases of compressive load, if the changes in stiffness are sufficient to cause the structure's stiffness to drop to zero, buckling occurs and the structure experiences a rapid deformation. It then either falls apart or acquires a new stiffness in its post buckling state. Linear buckling analysis can be used to calculate the load under which a structure will buckle (Euler load). However, the results of linear buckling analysis are not conservative. In addition, idealizations in the FEA model may result in the predicted buckling load being much higher for the FEA model than for the real part. Thus the results of linear buckling analysis should be used carefully.Buckling does not necessarily equal catastrophic failure and the structure may still be able to support the load after buckling has taken place. Nonlinear analysis will explain post buckling behaviour.

\section{THE FEM MODEL AND PROCEDURE}

Finite element analysis (FEA) is one of the most popular engineering analysis methods for Non linear problems. FEA requires a finite element mesh as a geometric input. This mesh can be generated directly from a solid model for the detailed part model designed in a three-dimensional (3D) CAD system. Since the detailed solid model (see Fig. 1) is so simple to analyses efficiently, some simplification with an appropriate idealization process including changing length of overlapping plate, no. of sub steps during the analysis and reducing mesh size in the FE model is needed to reduce the excessive computation time. The welded flat plates are made of up mild steels or structural steels; a different type of meshing approach is required. For analysis such a welded flat plates, we extracted and meshed the mid-surface using 20 node Hexagonal rectangular elements. [3]

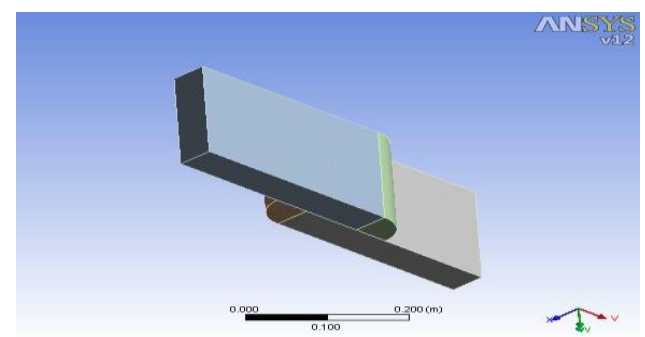

Figure 1: Finite Element Models for welded flat plates

Fig. 1 shows the FEM model of the existing design. The existing design has two flat plates. One plate is fixed from one end and other plate is given an axial loading for checking failure ultimate strength of a weld joint. The material used for Finite Element Analysis is Non Linear. The FEM Model having 6 freedoms: translations in the nodal $\mathrm{x}, \mathrm{y}$, and $\mathrm{z}$ directions and rotations about the nodal $\mathrm{x}, \mathrm{y}$, and $\mathrm{z}$-axes. 


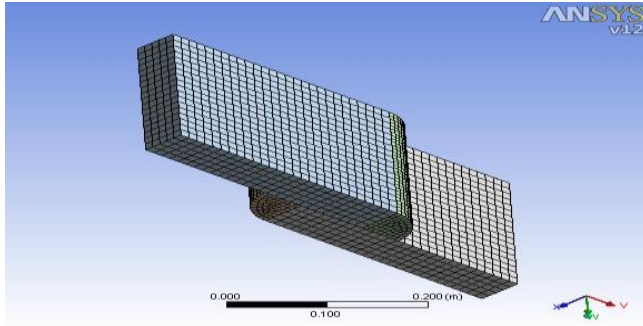

Figure 2: FE Mesh Model welded flat plate.

Material properties applied to the body contains

Young's Modulus: $210 \mathrm{GPa}$

Poisson's Ratio: 0.23

Yield Strength: $230 \mathrm{MPa}$

Tangent Modulus: $10 \mathrm{GPa}$

Ultimate Strength: $360 \mathrm{MPa}$

the boundary conditions applied for the plates which is having one end is fixed or fixed supports and while other is having applied linear load on plate as shown in the fig.3and 4

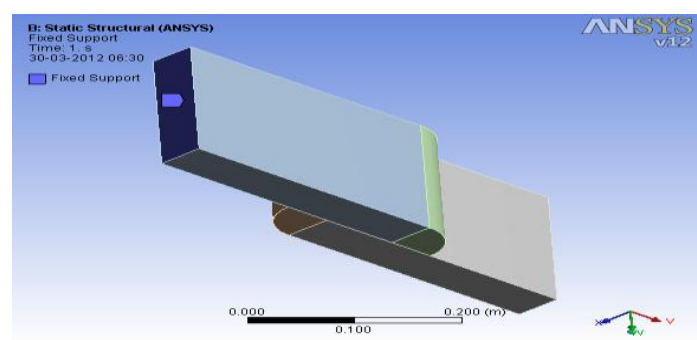

Figure 3: Fixed suppot is provided for one flat plates

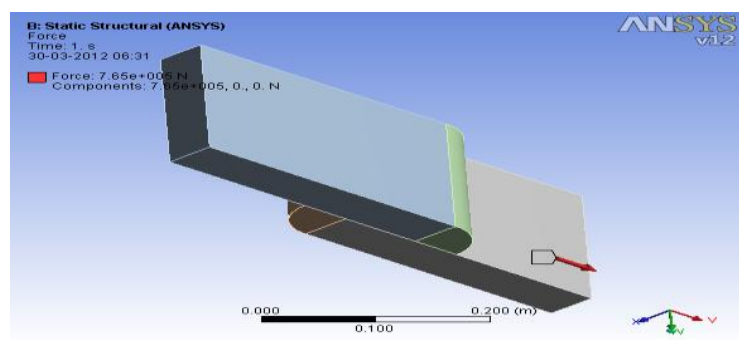

Figure 4: Application of boundry condition as force on another plate

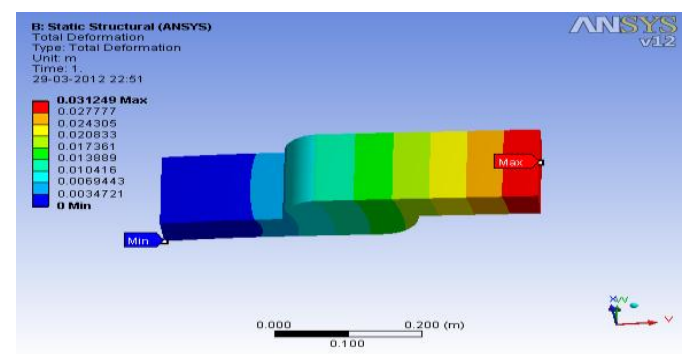

Figure 5: Total deformation of plate and joint with 15 substeps

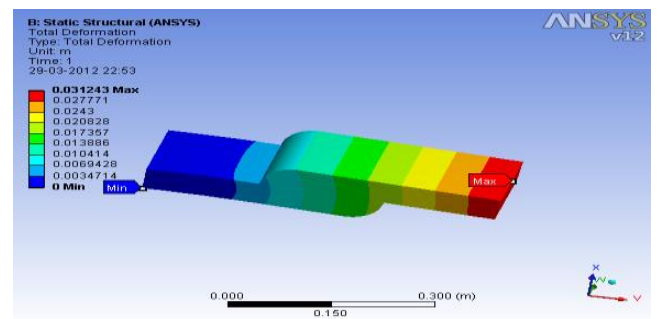

Figure 6: Total deformation of plate and joint with 20 substeps 


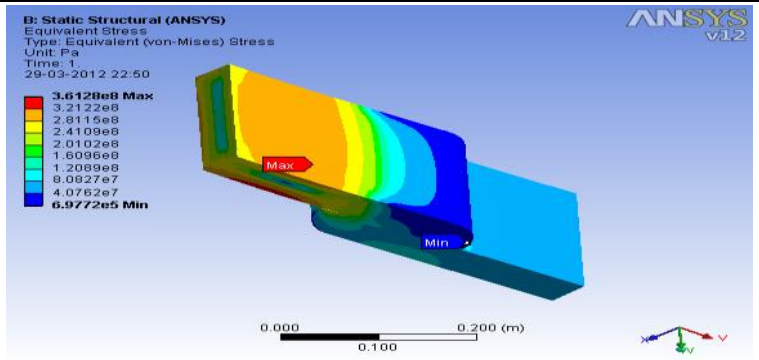

Fig.7 Equivalent(Von-Mises)stresses in the welded flat plate with 15 substeps

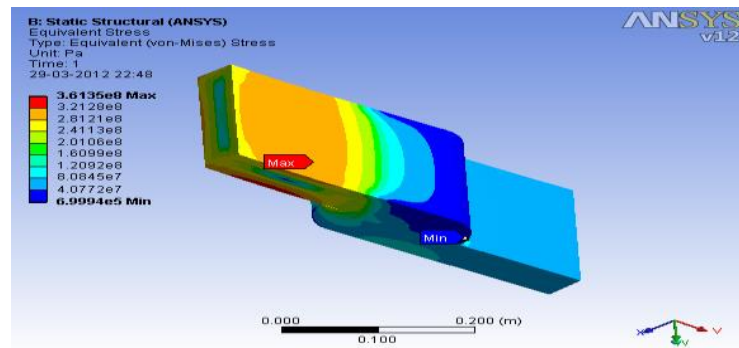

Fig.8 Equivalent(Von-Mises)stresses in the welded flat plate with 20 substeps

\section{RESULTS AND CONCLUSION}

After doing no. of iterations we get different values of maximum stress corresponding deformations maximum load that can be sustain by the model. So different graph are plotted on the basis of the that data

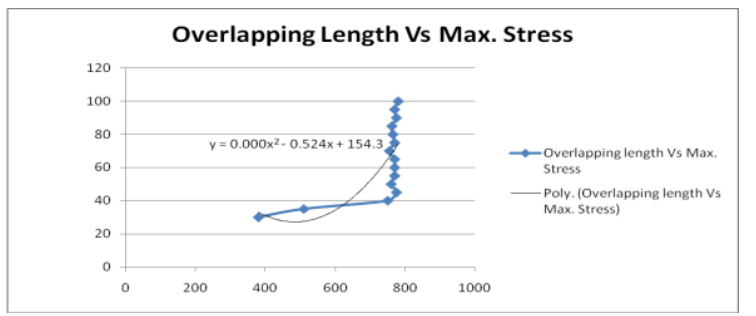

Figure 9: Graph of Overlapping Length Vs Maximum stress

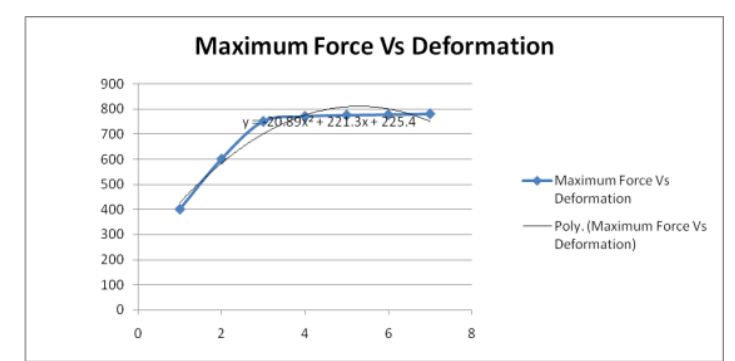

Figure 10: Graph of Maximum Force Vs Deformation

\begin{tabular}{|c|c|c|}
\hline FORCE $(\mathrm{KN})$ & $\begin{array}{c}\text { MAX } \\
\text { STRESS }\left(\mathrm{N} / \mathrm{m}^{2}\right)\end{array}$ & $\begin{array}{c}\text { DEFORMATION } \\
(\mathrm{m})\end{array}$ \\
\hline 400 & $2.87 \mathrm{E}+08$ & $3.76 \mathrm{E}-03$ \\
\hline 600 & $2.67 \mathrm{E}+08$ & 0.010216 \\
\hline 700 & $3.20 \mathrm{E}+08$ & 0.022278 \\
\hline 750 & $3.52 \mathrm{E}+08$ & 0.029121 \\
\hline 765 & $3.61 \mathrm{E}+08$ & 0.031249 \\
\hline 762 & $3.59 \mathrm{E}+08$ & 0.030821 \\
\hline
\end{tabular}

Table no. 1 results obtained under the analysis of $85 \mathrm{~mm}$ of overlapping length and 15 sub steps of non linear FEA.

From above discussion it is concluded that as the Overlapping length increase strength of the joint increases. From above table as value of force increases gradually slightly the Von Mises stress value increases and correspondingly deformation value is varying. It is observed during iterations the stress value is decreased after it crosses Ultimate strength value. 
This work is also useful in the analysis of welded curved plate which are used in the boiler manufacturing, ship building. For producing complicated parts or welding of curved surfaces is done on workers experience, skill and knowledge. So still large scope available in this field.

\section{ACKNOWLEDGMENT}

The authors would like to thank to the Vaftsy CAE Pune, India. for supplying the experimental results in this study.

\section{REFERENCES}

[1] Dean Deng, Hidekazu Murakawa, Wei Liang "Prediction of Welding distortion in a curved plate structure by means of elastic finite element method" Published in journal of Material Processing Technology 203(2008) page no. 252-266

[2] Hyungyil Lee, Nahmho Kim, Tae Soo Lee Crack trajectory near a weld: Modeling and simulation published in Engineering Fracture Mechanics 72(2005) page no. 1203-1221

[3] A Joseph, Sanjai K. Rai, T Jaikumar "Evaluation of residual stresses in dissimilar weld joint" published in International Journal of Pressure Vessels' and piping 82 (2005) page No. 700-705

[4] Donald w. White and Se-Kwon Jung "Shear strength of horizontally curved steel I-girders finite element analysis studies" Journal of constructional steel research 62 (2006) Page no. 329-342

[5] Chien-Yuan Hou "Fatigue analysis of welded joints with the aid of real three-dimensional weld toe geometry" published in International Journal of Fatigue 29(2007) Page no. 772-785

[6] M.M. Rashid, V. Tvergaard "Crack trajectory near a weld: Modeling and simulation" published in engg. Fracture 75(2008) 560570 .

[7] V.B. Bhandari "Design of Machine Element”, Published by Tata McGraw Hill Publishing Company Limited New Delhi.

[8] Joseph Edward Shigley “Mechanical Engineering Design”, First Metric Edition by McGraw Hill Company New Delhi.

[9] S.S.Bhavikatti "Finite Element Method" second edition New Age International Publication.

[10] J.N. Reddy “An Introduction to Finite Element Method" third edition Tata McGraw Hill Edition.

[11] Design of steel structure by S.R. Satish Kumar and Prof. A.R. Santh Kumar Indian Institute of Technology Madras

[12] Manufacturing Processes for Engineering Materials, 5th ed. Kalpakjian $\bullet$ Schmid C2008, Pearson Education

[13] M. Xie,*, J.C. Chapman "Static and fatigue tensile strength of friction-welded bar-plate connections embedded in concrete" published in Journal of Constructional Steel Research 61 (2005) 651-673

[14] Yu LUO, Morinobu ISHIYAMA and Hidekazu MURAKAWA "Welding deformation of plate with longitudinal curvature" Trans JWRI Vol. 28,(1999) No.2 